\title{
Extended sandwich patch technique to repair ventricular septal rupture
}

\author{
Tohru Asai $^{1,2}$, Takeshi Kinoshita ${ }^{2}$, Atsumi Oishi ${ }^{1}$, Kohei Hachiro ${ }^{2}$, Tomoaki Suzuki ${ }^{2}$ Piers Vigers $^{2}$ \\ ${ }^{1}$ Department of Cardiovascular Surgery, Juntendo University, Tokyo, Japan; ${ }^{2}$ Division of Cardiovascular Surgery, Shiga University of Medical \\ Science, Otsu, Japan \\ Correspondence to: Tohru Asai. Department of Cardiovascular Surgery, Juntendo University, Hongo 2-1-1, Bunnkyo-ku, Tokyo 113-8421, Japan. \\ Email: t.asai.jj@juntendo.ac.jp.
}

Submitted Aug 30, 2021. Accepted for publication Jan 27, 2022.

doi: 10.21037/acs-2021-ami-164

View this article at: https://dx.doi.org/10.21037/acs-2021-ami-164

\section{Introduction}

This article describes the surgical techniques demonstrated in our video, "The extended sandwich patch repair for acute posterior ventricular septal rupture (VSR)".

Postinfarction VSR can be lethal, and its repair has proved technically challenging, particularly for patients needing repair in the very acute phase, and with posteriortype VSR. A recent large study reported operative mortality over $50 \%$ when attempted within seven days after myocardial infarction (1). Also, surgical mortality may be twice as high in posterior VSR cases compared to anterior cases (2). We have developed the extended sandwich patch technique via right ventriculotomy, aiming to improve surgical outcomes by eliminating all risk of shunt recurrence, even in the very acute phase and in posterior VSR cases (3).

\section{Clinical vignette}

A 62-year-old diabetic man presented following a week of chest discomfort. He was diagnosed with inferior myocardial infarction and underwent percutaneous coronary intervention (PCI) for a totally occluded proximal right coronary artery (RCA). The coronary angiogram also showed $90 \%$ stenosis of his proximal left anterior descending artery (LAD). Several hours after the PCI, he became hypotensive. Echocardiography showed a VSR at the base of his ventricular septum. He was emergently transferred to our hospital. As per our policy for VSR complicated with cardiogenic shock, the patient was transferred to the operating room.

\section{Surgical technique}

\section{Preparation}

General anesthesia was induced and an intra-aortic balloon pump (IABP) was inserted before the operation. A radial arterial line, a Swan-Ganz catheter and a probe for transesophageal echocardiography (TEE) were introduced. Massive left-to-right shunt flow was confirmed by color doppler mode. The patient was prepared in the usual fashion.

\section{Exposition}

This patient had an acute posterior VSR plus non-culprit coronary artery lesions. We planned an extended sandwich patch repair via right ventriculotomy, plus concomitant double coronary artery bypasses.

\section{Operation}

We harvested the left internal thoracic artery (LITA) and a saphenous vein segment. We instituted the cardiopulmonary bypass, with ascending aorta, bicaval and left ventricle (LV) vent cannulation. We palpated the point of maximal intensity of thrill, which was at the base of the inferior wall. We clamped the ascending aorta, and began cold blood cardioplegia through the aortic root, and retrograde cardioplegia through a cannula secured in the coronary sinus with a purse-string suture. We put moist pads in the oblique sinus and verticalized the heart to expose the inferior aspect of the heart. 
We made an incision several centimeters long in the right ventricle (RV) wall, one centimeter away from, and parallel to, the posterior descending artery (PDA). We resected the coarse trabeculated muscles in the RV around the defect, then debrided enough of the necrotic muscle at the margin of the defect to allow a Dacron patch to be passed through the defect into the LV. For the sandwich patch procedure, we cut two Dacron patches, large enough to overlap the defect margin by at least $1.5 \mathrm{~cm}$. Octagonal patches of about $6 \mathrm{~cm}$ in diameter have typically been found suitable. Before inserting the $\mathrm{LV}$-side patch, we sutured the margin of the patch with eight 3-0 polypropylene sutures with a large MH needle (Ethicon, Inc., Somerville, NJ, USA) in a mattress fashion. We passed the suture needles into the $\mathrm{LV}$ through the defect, then brought them out through the LV wall transmurally or transeptally, a safe distance from the defect margin. We used the sutures brought transeptally back into the RV cavity to secure the RV-side patch, and secured the sutures brought out of the heart with large Teflon felt pledgets. Before we tied the final suture, we inserted BioGlue Surgical Adhesive (CryoLife, Kennesaw, GA, USA) into the defect between the patches. Then we closed the right ventriculotomy with 3-0 polypropylene and reinforcing felt strips.

We completed the coronary bypass grafting to the LAD using the LITA, and to the branch of the RCA using the saphenous vein.

\section{Completion}

Finally, we weaned the patient off cardiopulmonary bypass. TEE showed good LV function, and no residual shunt was detectable by color doppler mode. We found no significant oxygen saturation step-up between superior vena cava and pulmonary artery blood samples. The cardiopulmonary bypass time was 164 minutes and aortic cross clamp time was 126 minutes. The IABP and the endotracheal tube were removed the day after the operation. The patient recovered uneventfully.

\section{Comments}

In our experience of thirty-five cases of VSR, most were repaired within seven days. Of these, two patients received reoperative repair after the first repair due to another new peripheral defect, and their thirty-day mortality was $17 \%$.

A serious source of poor outcomes, particularly in the very acute period and in posterior VSR, is shunt recurrence (4). To minimise the risk of sutures tearing out, a patch with a wide safety-margin around the defect is essential for safety during the acute phase, as it is impossible to predict accurately how much of the tissue peripheral to the defect may become friable after surgery. We believe that fullthickness transseptal/transmural mattress sutures are far less likely to tear out than partial-thickness running sutures.

The extended sandwich patch technique via right ventriculotomy has the following advantages. Firstly, shunt recurrence is rare if the sandwich patch covers a large margin around the defect. Secondly, postoperative bleeding and potential left ventricular functional damage are minimal with avoidance of left ventriculotomy. Thirdly, the same technique can be employed in both anterior and posterior VSR, with a correctly placed right ventriculotomy, close and parallel to the infarct culprit artery (the LAD or the PDA), to minimize RV damage (5).

There are some caveats however. Firstly, the right ventriculotomy must be made with care; if an artery supplying the ventricle wall is damaged, that part of the ventricle may be harmed, creating a new problem. Secondly, the LV-side patch must be large enough to cover the whole defect plus a peripheral margin of safety. In this case, as in most in our experience, an octagon of approximately 6 $\mathrm{cm}$ diameter suffices, but for a larger and perhaps irregular defect, a patch must be cut to fit.

\section{Acknowledgments}

Funding: None.

\section{Footnote}

Conflicts of Interest: Dr. TA developed the "extended sandwich patch technique". The other authors have no conflicts of interest to declare.

Open Access Statement: This is an Open Access article distributed in accordance with the Creative Commons Attribution-NonCommercial-NoDerivs 4.0 International License (CC BY-NC-ND 4.0), which permits the noncommercial replication and distribution of the article with the strict proviso that no changes or edits are made and the original work is properly cited (including links to both the formal publication through the relevant DOI and the license). See: https://creativecommons.org/licenses/by-nc-nd/4.0/. 


\section{References}

1. Arnaoutakis GJ, Zhao Y, George TJ, et al. Surgical repair of ventricular septal defect after myocardial infarction: outcomes from the Society of Thoracic Surgeons National Database. Ann Thorac Surg 2012;94:436-43; discussion 443-4.

2. Komeda M, Fremes SE, David TE. Surgical repair of postinfarction ventricular septal defect. Circulation 1990;82:IV243-7.

3. Asai T, Hosoba S, Suzuki T, et al. Postinfarction

Cite this article as: Asai T, Kinoshita T, Oishi A, Hachiro K, Suzuki T, Vigers P. Extended sandwich patch technique to repair ventricular septal rupture. Ann Cardiothorac Surg 2022;11(3):337-339. doi: 10.21037/acs-2021-ami-164 ventricular septal defect: right ventricular approach-the extended "sandwich" patch. Semin Thorac Cardiovasc Surg 2012;24:59-62.

4. Asai T. Postinfarction ventricular septal rupture: can we improve clinical outcome of surgical repair? Gen Thorac Cardiovasc Surg 2016;64:121-30.

5. Kinoshita T, Asai T, Hachiro K, et al. Extended Sandwich Patch Technique via Right Ventriculotomy for Acute Ventricular Septal Rupture. Ann Thorac Surg 2022;113:1200-7. 